Jun 19th, 9:00 AM - 10:20 AM

\title{
Trade-offs of biogas production: comparing crop rotations under different climate scenarios
}

\author{
Sven Lautenbach \\ University Bonn, Institute for Geodesy and Geoinformation, UFZ Helmholtz Centre for Environmental \\ Research, sven.lautenbach@uni-bonn.de \\ Martin Volk \\ UFZ Helmholtz Centre for Environmental Research \\ Micheal Strauch \\ UFZ Helmholtz Centre for Environmental Research \\ Gerald Whittaker \\ USDA, ARS, National Forage Seed Production Research Center \\ Ralf Seppelt \\ UFZ Helmholtz Centre for Environmental Research
}

Follow this and additional works at: https://scholarsarchive.byu.edu/iemssconference

Part of the Civil Engineering Commons, Data Storage Systems Commons, Environmental Engineering Commons, Hydraulic Engineering Commons, and the Other Civil and Environmental Engineering Commons

Lautenbach, Sven; Volk, Martin; Strauch, Micheal; Whittaker, Gerald; and Seppelt, Ralf, "Trade-offs of biogas production: comparing crop rotations under different climate scenarios" (2014). International Congress on Environmental Modelling and Software. 38.

https://scholarsarchive.byu.edu/iemssconference/2014/Stream-H/38

This Event is brought to you for free and open access by the Civil and Environmental Engineering at BYU ScholarsArchive. It has been accepted for inclusion in International Congress on Environmental Modelling and Software by an authorized administrator of BYU ScholarsArchive. For more information, please contact scholarsarchive@byu.edu, ellen_amatangelo@byu.edu. 


\title{
Trade-offs of biogas production: comparing crop ro- tations under different climate scenarios
}

\author{
Sven Lautenbach ${ }^{\mathrm{a}, \mathrm{b}}$, Martin Volk ${ }^{\mathrm{b}}$, Michael Strauch ${ }^{\mathrm{b}}$, Gerald Whittaker ${ }^{\mathrm{c}}$, Ralf Seppelt ${ }^{\mathrm{b}}$ \\ a University Bonn, Institute for Geodesy and Geoinformation, Nußallee 1, 53115 Bonn, Germany, \\ sven.lautenbach@uni-bonn.de \\ b UFZ Helmholtz Centre for Environmental Research, Department of Computational Landscape \\ Ecology, Permoserstr. 15, 04318 Leipzig, Germany \\ c USDA, ARS, National Forage Seed Production Research Center, 3450 SW Campus Way, Corvallis, \\ OR $97331-7102$
}

\begin{abstract}
While increasing biofuel production is worldwide on the political agenda, concerns about the involved trade-offs are on the rise. However, the quantification of these trade-offs is typically based on the comparison of a limited number of plausible alternatives. We extended the analysis by applying a multi-objective genetic algorithm to estimate the set of Pareto optimal solutions which describe the trade-offs between the objectives. The Pareto solutions represent the (estimated) best options given the model and the specified control options. Our analysis studied food and fodder based crop rotations and two alternative biogas crop production schemes: a corn based production scheme and a two-culture production scheme which combines a summer and a winter crop. The integrated river basin model SWAT was used to evaluate the effects of the different production schemes on bioenergy crop production, food and fodder crop production, water quality and low flow discharge. The analysis took place in a medium sized agricultural watershed $\left(\sim 320 \mathrm{~km}^{2}\right)$ in Central Germany. We run the optimization algorithm for combinations of the three sets of crop rotations to identify the trade-offs. The two biogas crop rotation schemes showed significant differences in their trade-offs with water quality and low flow conditions. High corn yields led to increasing nitrate concentrations while high bioenergy crop yields based on the two culture system led to decreases in low flow. But trade-offs depended on the choice of food and fodder crops as well. To assess the robustness of the solutions, we compared trade-offs under current climate conditions with trade-offs under two climate scenarios (A1B and B1 scenarios statistically downscaled by WEREX-IV approach for the time period 20142100). The estimated trade-offs differed significantly under the different climate conditions, highlighting thereby that trade-off analysis has to consider changing boundary conditions.
\end{abstract}

Keywords: River basin management; Ecosystem Services; trade-offs; bioenergy; land use; optimization

\section{Introduction}

Decision makers in environmental management are confronted with a complex context in which the outcomes of management decisions and the associated trade-offs between different objectives cannot easily be foreseen. Simulation models can play an important role in informing decision makers about the likely outcomes of management options. But the range of potential options is typically rather large. Therefore, efficient ways to identify suitable options are needed.

The demand for increasing bioenergy production is a showcase example for the conflicts that occur due to conflicting demands under limited land availability. While the target for bioenergy production has already been set by legislation, a quantitative evaluation of the costs and benefits of bioenergy production is at its beginning. At present, the first generation bioenergy crops compete with food and fodder production on arable land. Negative effects of increasing bioenergy production are expected (Fargione et al., 2010; Gasparatos et al., 2011; Tilman et al., 2009). However, quantification of the trade-offs among objectives in bioenergy crop production is problematic, and the number of studies 
that have been published on that topic is still limited. Usually, trade-offs have been quantified based on a comparison of plausible scenarios, but do not consider whether the reported trade-offs are optimal or not. Therefore, the solutions found might be sub-optimal with respect to other land management options that have not been included in the limited set of scenario options. Decisions based on the trade-offs derived from such a scenario analysis are therefore likely to lead to sub-optimal outcomes as well. The use of a multi-objective optimization of land use will help to overcome that problem (Seppelt et al., 2013).

Optimization algorithms have been widely used in environmental modeling. An overview about the many different applications of evolutionary algorithms in water related research is provided by Reed et al. (2013) and Nicklow et al. (2010). Lautenbach et al. (2013) used the river basin management model SWAT together with the NSGA-II optimizer to assess trade-offs between increasing biodiesel production and water quality and water quantity. Klein et al. (2013) used a genetic algorithm together with a weighting approach to optimize adaptation strategies for agricultural land under climate change. Maringanti et al.(2009) and Rodriguez et al. (2011) used SWAT and NSGA-II to identify the spatial allocation of best management practices (combinations of pasture management, buffer zones, and poultry litter application practices). Panagopoulos et al. (2012) used SWAT and NSGA-II to optimize the placement of fifty different best management practices (livestock, crop, soil and nutrient application management in alfalfa, corn and pastureland fields) with respect to cost, phosphorus and nitrogen emissions. Whittaker (2005) applied the same model chain used in our analysis to assess trade-offs between agriculture and salmon habitat protection.

The aim of the study was to identify functional trade-offs between biogas crop production, food and fodder production, water quality and discharge under low flow conditions. Furthermore, our objective was to spot the effects that different crop rotations have with respect to the four objectives mentioned previously. We assume all solutions initially have equal preference during the search process. The preferences of decision maker could be expressed in a later step during the exploration of trade-offs and the selection of design solutions.

\section{Methods and data}

The analysis was based on a watershed model that has been parameterized for our case study. During the calibration, model parameters were adjusted to achieve good model performance (cf. Figure 1). The best fitting model parameterization was then employed to an optimization algorithm to find and identify the Pareto-optimal solutions which can be interpreted as functional trade-offs between the different objectives. In a last step, the model was rerun for all Pareto-optimal crop rotation allocations. This time, in addition to low flow and nitrate concentration the yields for all crops were recorded. These yields together with the low flow and nitrate concentration values were used to detect clusters in the data using a self organizing map (SOM). In addition a generalized additive model was run to detect non-linearity in the relationship between low flow and nitrate concentration and the individual crop yields.

We used the Soil Water Assessment Tool (SWAT, Arnold and Fohrer, 2005) to model the effects of different land use options on water quality and discharge. SWAT is a physically-based, conceptual, continuous-time river basin model with spatially semi-distributed parameters operating on a daily time step. It was designed to simulate broader scale patterns of discharge and water quality in the spatial and temporal domain (Neitsch et al., 2005). The SWAT model integrates all relevant processes including water flow, nutrient transport and turnover, vegetation growth, land use, and water management at the sub-basin scale. It considers five different pools of nitrogen in the soils (Neitsch et al., 2005): two inorganic (ammonium and nitrate) and three organic (fresh organic nitrogen and active and stable organic nitrogen). Nitrogen is added to the soil by fertilizer, manure or residue application, fixation by bacteria, and atmospheric deposition. Nitrogen losses occur by plant uptake, leaching, volatilization, denitrification and erosion. The area of the case study watershed was divided into 6 subbasins based on a digital elevation map. SWAT uses the concept of hydrological response units (HRU) to further subdivide the sub-basins. The HRUs contain similar terrain, similar soil characteristics, and similar land use. For our application, the area was divided into $53 \mathrm{HRUs}$. The water balance for each HRU is represented by four storages that consist of snow, soil profile, shallow aquifer, and deep aquifer. The soil profile can be subdivided into as many as ten soil layers - we used seven soil types with up to five soil layers in our case study. Soil water processes include evaporation, surface 
runoff, infiltration, plant uptake, lateral flow, and percolation to lower layers. The surface runoff from daily rainfall is estimated with a modification of the SCS curve number method (Arnold and Allen, 1996; Neitsch et al., 2005). The different runoff components and matter fluxes are routed to the subbasin outlets, where modeled and observed discharge as well as water quality data can be compared.

The model was calibrated for monthly streamflow and nitrate load at gauge Thekla using the Generalized Likelihood Uncertainty Estimation (GLUE) method (Beven and Binley, 1992). Calibration period was from 1992 to 2002, in which data on nitrate were only available in sufficient quality from 1999 to 2002. Based on an initial sensitivity analysis and on previous experience with the calibration of the model, a set of parameters was selected for use in calibration. Calibration ranges and default values of the other parameters were specified using recommendations given by the model developers (Neitsch et al., 2005). The model was calibrated simultaneously for both discharge and nitrogen load. Finally, crop yields were checked for plausibility based on information provided by the agricultural statistics for the NUTS 4 level. Due to the few time series where both nitrate and streamflow data were available, the model was validated only for streamflow (for the period from 2003 to 2007). Overall, model performance was satisfactory with NashSutcliff efficiency values of 0.52 (calibration) and 0.70 (validation) for predicting streamflow and 0.67 for predicting nitrate load. In the trade-off analysis, we used only the best selected model to assess the effects of the different management schemes.

The use of an optimization approach requires that both control variables (which specify the range of management options) and objectives (which specify how the result of different management options should be compared) need to be defined. The control variables were de-

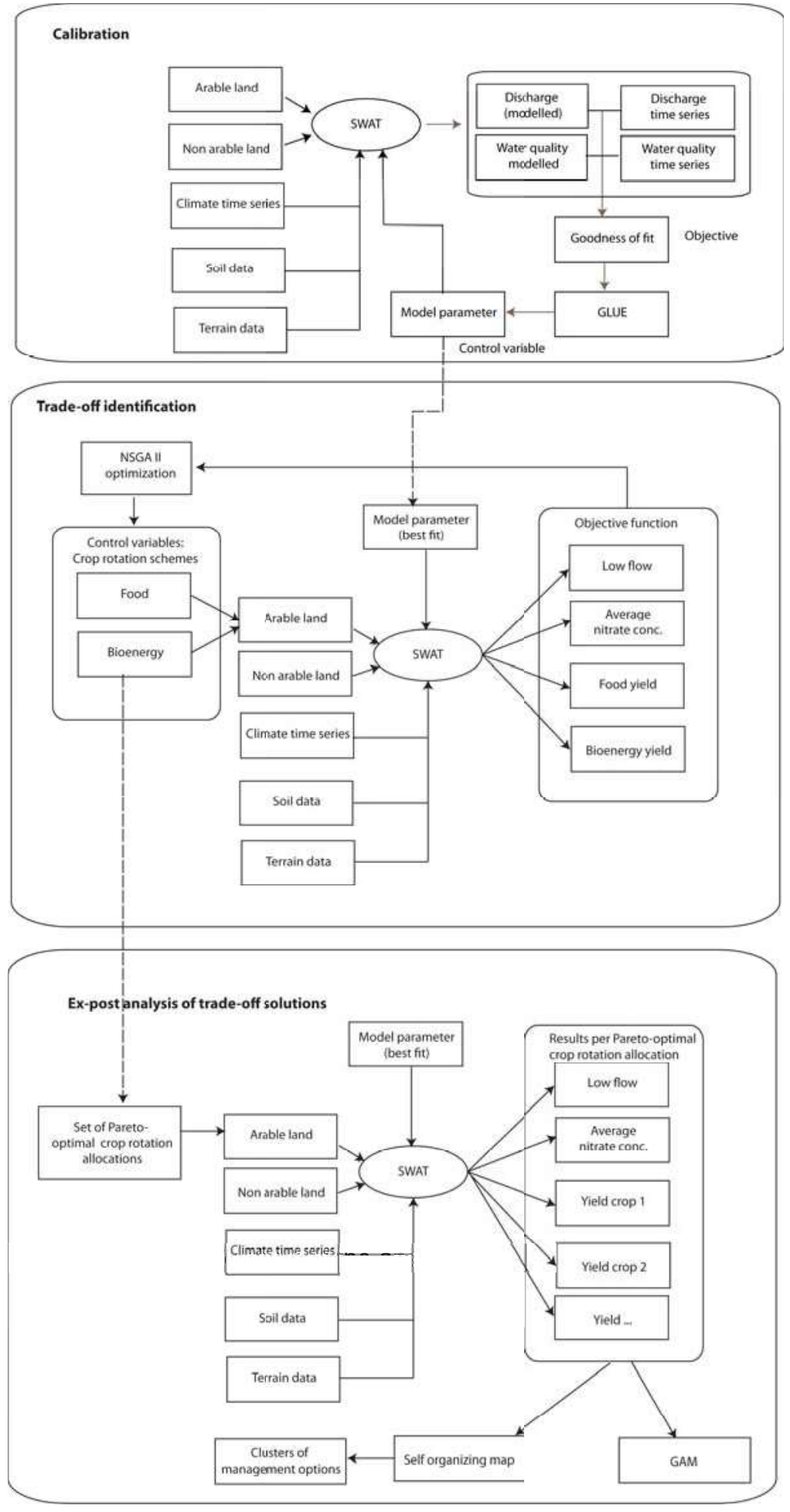

Figure 2. Flowchart of the analysis 
fined as a set of predefined crop rotations with associated management practices. During the optimization run different spatial allocations of the crop rotations were tested. The range of management options during the optimization was defined by a fixed set of 39 crop rotations: 13 food and fodder crop rotations, 13 crop rotations in which corn production had been increased for biogas production and 13 crop rotations based on a two culture system for biogas production. These crop rotations were derived based on crop rotations used in the region - winter wheat, winter barley, winter rye, triticale, sugar beets, silage corn, alfalfa, ley, rapeseed and potatoes were farmed in the region. We prepared crop rotations representing only food and fodder production by eliminating rapeseed (which is mainly used for biodiesel production in the EU) from the crop rotations currently used in the region. For the corn based biogas crop rotations, we increased the share of corn up to $30 \%$ in the crop rotations. The crop rotations for the biogas production based on the two culture system combined a summer crop such as corn, sunflowers or sorghum with a winter crop such as winter wheat or winter barley. This represents a very intensive management system with two harvests per year. However, the winter crop was harvested quite early to allow cultivation of the summer crop in the second half of the growing season. Therefore, winter crop yields in the two culture system were significantly lower than those of winter crops grown for food production. Harvest for the biogas production considered the whole crop. Residuals of the biogas production were used as fertilizer input on the fields.

Roughly $60 \%$ of the catchment area was covered by arable land, represented in the model by 13 of the 53 HRUs. There was no economic or biophysical reason for other land use allocations. Therefore, we decided to remain forest, pasture, water and residential areas in their current use, and to modify only the crop rotation schemes on existing farmland areas - i.e. only these 13 HRUs were considered in the optimization approach. Each crop rotation was tagged with a unique ID. This ID was then used to map crop rotation schemes to the HRUs in the genetic algorithm. Each crop rotation scheme was associated with a set of management actions such as tillage and fertilizer application. These management schemes reflect current practice in the case study region.

We specified four objective functions to be maximized in the optimization:

1. maximize harvested yield of food crops used (yield food and fodder), measured in tons dry weight, summed over the whole period,

2. maximize harvested yield for bioenergy crops (yield bioenergy) in tons dry weight, summed over the whole period,

3. maximize average monthly discharge under low flow conditions (low flow), measured as the 5 percentile of discharge at the gauging station Thekla in $\mathrm{m}^{3}$ per second

4. minimize the 95 percentile of the $\mathrm{NO}_{3}^{-}$concentration at the gauging station Thekla in $\mathrm{mg} \mathrm{N}$ per liter (nitrate concentration).

We used the epsilon non dominated sorting genetic algorithm NSGA-II (Kollat and Reed, 2006) for the optimization of our four-dimensional objective function. The genome consisted of the list of the crop rotation schemes applied to the agricultural HRUs. Since our model setup consisted of 13 agricultural HRUs, the genome was defined as an array of 13 integers - each integer representing a crop rotation from the set of crop rotations available. The initial population is created by assigning crop rotations from the set of available crop rotation to the HRUs. If two individuals are selected for mating, crossover is performed such that the arrays of both parents are split at a randomly chosen position and the four parts are recombined. Since the objective function is 4-dimensional, the individuals are assigned ranks based on a non-dominated sorting scheme: an individual is dominated by another individual if the other individual has a better fitness value in one dimension of the objective function, while having the same or better fitness value in all the other dimensions (cf. Figure 3). Each individual gets a score based on the number of individuals that dominate it. All individuals that have the same number of dominating individuals are said to belong to one front. The final outer-most front defines the Pareto front. For each individual on that front, any one objective cannot be improved without losing some quantity of the other objectives - this describes the trade-offs between the objectives.

Since one is interested in a Pareto front estimate that approximates the complete Pareto set, a "crowding distance" is defined which puts selection pressure on the algorithm to select individuals from the feasible range of the Pareto set. Crowding distance refers to the search space around the individual that is not occupied by another individual in the population. If the number of individuals on the Pareto front is larger than the predefined size $\mathrm{N}$, individuals are selected based on their crowding distance. Individuals that are close together will be removed from the population to allow for a large 
spread of the individuals in the objective space. The crowding distance is also used during the selection of individuals, which are allowed to mate.

Communication of results of a multi-objective optimization is an important but non-trivial issue especially in high dimensional objective and/or design/decision spaces. Visualization of results has been identified as a key topic (Kollat and Reed, 2007). To simplify the complex shape of the Pareto frontier we searched for clusters in the non-dominated solutions. We employed a SOM (Kohonen, 2008) for that purpose. The clustering was based on the crop specific yields for each solution together with the low flow and the average nitrate concentration. Variables with a relatively low total yield were aggregated with similar crops. By including more management specific details in the cluster formation, the effect of different crops on the environmental objectives can be clearer identified. Prior to the clustering we normalized all variables by scaling them to zero mean and unit variance. The topology of the SOM was selected based on the criterion of the minimization of the quantification error (Bodt et al., 2002) applied in a bootstrap setting.

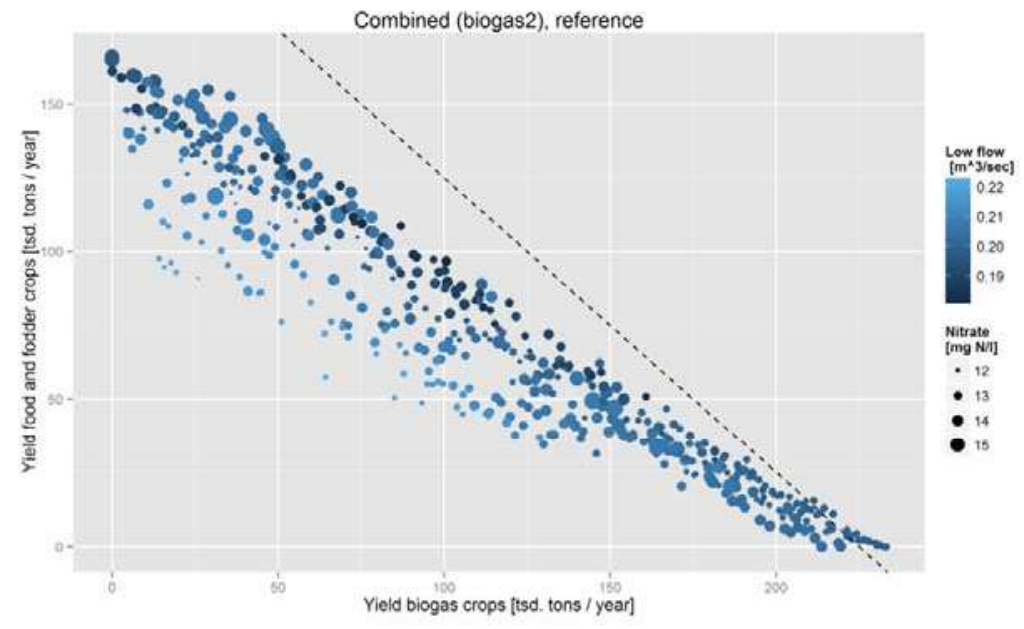

Figure 3. Scatterplot of the Pareto frontier for the recent climate. The Pareto frontier was calculated using all 39 crop rotations. The dashed line represents the $1: 1$ line and is intended to ease visual comparison between the results.

To assess the effect of varying climate conditions on the shape of the Pareto frontier, we ran the optimization and the ex-post analysis for the recent climate as well as for two regional climate scenario projections for the time period 2014-2100. We used the WEREX IV regionalization of the ECHAM5/ MPI-OM T63L31 climate projection for the IPCC A1B and B1 scenario (Spekat et al., 2006). The A1B scenario refers to climate change forced by economic growth in a globalized world assuming a balanced emphasis on all energy sources. The B1 scenario assumes a globalized world but one with a stronger focus on a green economy.

\section{$3 \quad$ Results}

Trade-offs between biogas crop production and food and fodder production were clearly visible (cf. Figure 3). However, a clear range of options existed for similar levels of crop production, depending on the crop rotations used and their spatial allocation. Overall, increasing biogas production along the Pareto frontier went along with both a decreasing low flow and decreasing nitrate concentrations in the river. For higher levels of food and fodder production trade-offs between nitrate concentration and low flow were present, depending on the role that silage corn or sugar beets played for food and fodder production. More environmental friendly solutions could have been reached with reduced production levels for both crops as long as bioenergy crop production stayed below round about 120 thousand tons per year, which equals 6.8 tons per ha crop land. 

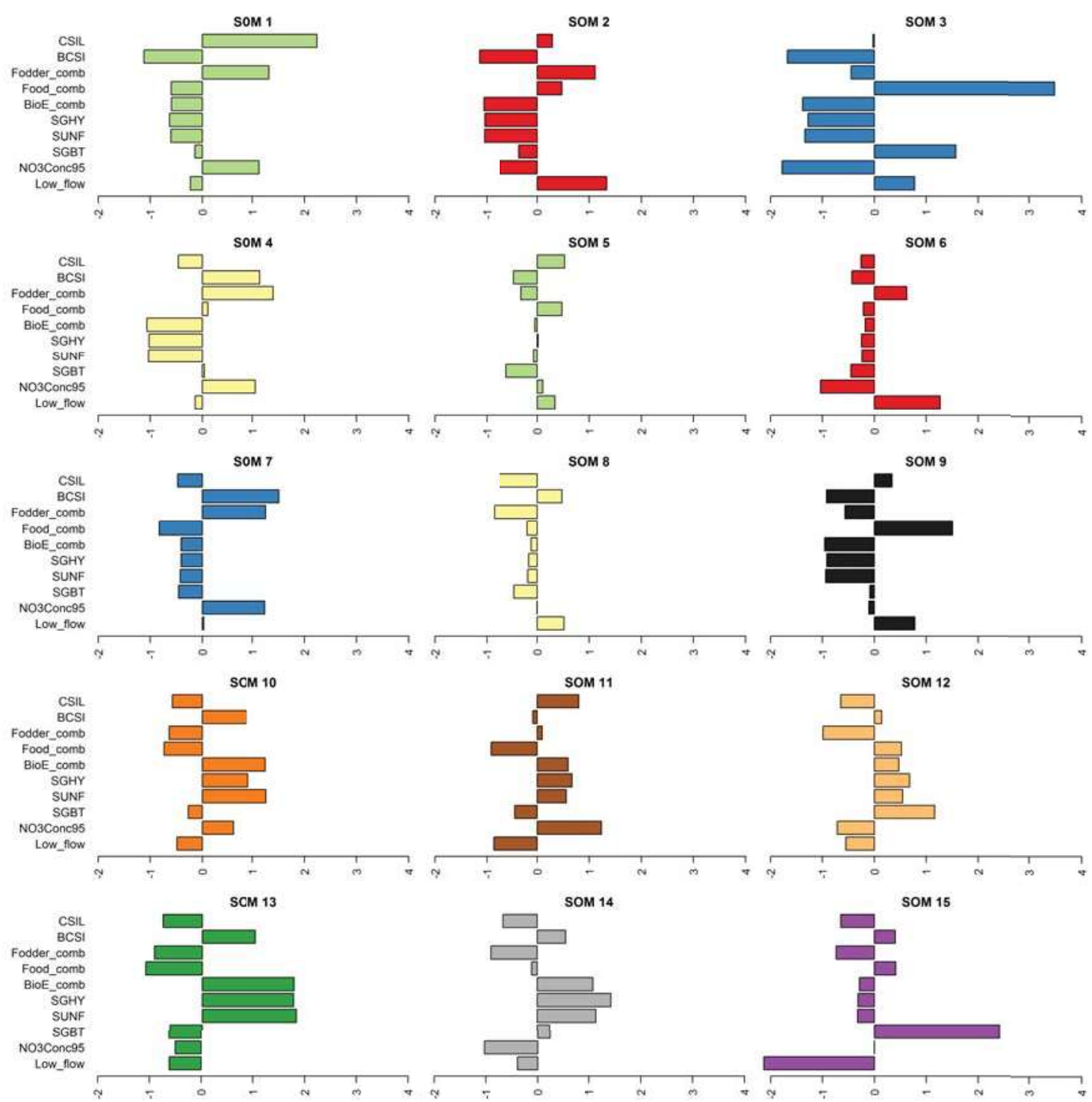

Figure 4. Clusters of the optimization under the reference climate based on a combination of all 39 crop rotations. The abbreviations represent low flow and nitrate concentration and the yields of the different crops: SGB: sugar beets, SUNF: sunflowers, SGHY: sorghum, BioE_comb: winter crops (barley, wheat, rye, triticale) used for bioenergy, Food_comb: crops (barley, wheat, rye, triticale, potatos) used for fodd production, Fodder_comb: ley and alfalfa, BCSI: corn for biogas, CSIL - silage corn. The values displayed were centered and standardized. The absolute values of the yields of the different crops varied notably.

The four-dimensionality of the objective function makes it hard to communicate results to stakeholders and decision makers. The clusters identified by the SOM simplified the detection of patterns in the Pareto-optimal solutions. Figure 4 shows the cluster centers identified by the SOM. Solutions with high yields for sugar beets showed decreased low flow levels (SOM 15 and 12) if the high sugar beet yield was not compensated by a drop in corn yield (SOM 3). Solutions with increased cereal production for food provisioning were characterized by increases in low flow (SOM 3 and 9). High yields for corn either for biogas (SOM 4 and 7 ) or fodder production (SOM 1) led to increased nitrate concentrations. Biogas production dominated by the two culture system was followed by decreased nitrate concentrations and a slightly decreased low flow if silage corn production was kept at a low level (SOM 13 and 14). If low levels of both food and biogas production were accepted and fodder production focused on ley and alfalfa, environmental conditions were best (SOM 2, 3 and 6). 


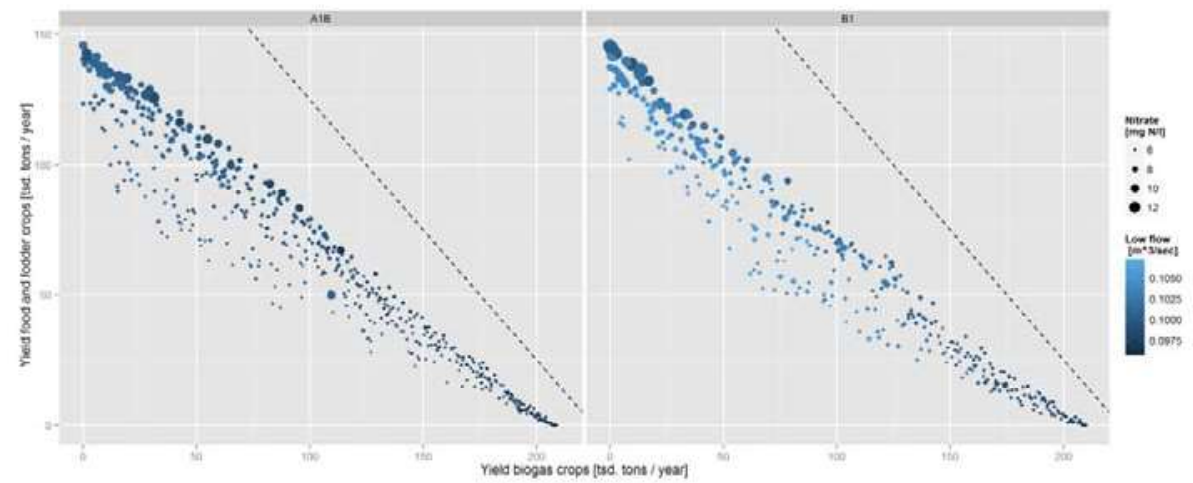

Figure 5. Scatterplot of the Pareto frontier for the combined optimization on all 39 crop rotations. The left panel shows the frontier for the A1B scenario while the right panel shows the frontier for the B1 scenario. The dashed line represents the $1: 1$ line and is intended to ease visual comparison between the results.

Model results depend on climate input parameters. Therefore, the shape of the Pareto frontier differs notably between the reference situation and the two climate scenarios as well as between the two climate scenarios (cf. Figure 5). The changed climate led to strong decreases in low flow as well as to a reduction of the 95 percentile of the nitrate concentration due to decreased nitrate leaching. Overall, Pareto optimal solutions under the B1 scenario show higher low flow conditions at the same level of bioenergy and food and fodder yields than under the A1B scenario. However, for high food and fodder yields B1 solutions show also higher 95 percentile nitrate concentrations than the A1B scenario solutions. For intermediate levels of bioenergy and food and fodder yields, A1B solutions allow slightly higher total yields. The two scenarios led also to different effects of the crops with respect to nitrate concentration and low flow (results not shown).

\section{Conclusions}

We showed that land use optimization identified a wide range of management options. This range of options is way beyond a classical scenario approach, which only tests a limited set of. Of course, the analysis was restricted to a number of constraints, namely the two biogas options and a fixed set of crop rotations and climate conditions.

Given the complexity of the Pareto frontiers in solution space of intermediate dimensionality we see a need to reduce complexity both for interpretation and for communication. The SOM approach used here showed promising results. Care should be taken incorporating full complexity in final management decisions. A suitable approach seems a hierarchical procedure in which first acceptable clusters are identified and later on solutions that fall into that clusters are analyzed in more detail. It is important to consider the constraints during the interpretation of the results. Changing climate conditions led to a markedly different shape of the Pareto frontier as well as to a different effect of the crops. Further work needs to identify robust solutions and to assess further uncertainties of the analysis.

\section{Acknowledgements}

This research was partly funded as a part of the CONNECT project (http://www.connectbiodiversa.eu/) by the ERA-Net BiodivERsA, with the national funder BMBF, part of the 2011 BiodivERsA call for research proposals. We gratefully acknowledge the colleagues from State Agency for Environmental and Agricultural Operations in Saxony (BfUL) for providing mean daily discharge data and climate data. Furthermore, we thank the colleagues from the Regional Council Leipzig for providing the monthly sampled water quality data of the gauge Thekla. Gudrun Schuhmann, from the UFZ helped to process the data. Ben Langenberg from the UFZ provided us support which enabled us to run our analysis on the high performance computing system of the UFZ. 


\section{References}

Arnold, J.G., Allen, P., 1996. Estimating hydrologic budgets for three Illinois watersheds. J. Hydrol. 176, 57-77.

Arnold, J.G., Fohrer, N., 2005. SWAT2000: current capabilities and research opportunities in applied watershed modelling. Hydrol. Process. 19, 563-572.

Beven, K.J., Binley, A., 1992. The future of distributed models: model calibration and uncertainty prediction. Hydrol. Process. 6, 279-298.

Bodt, E. De, Cottrell, M., Verleysen, M., 2002. Statistical tools to assess the reliability of selforganizing maps Statistical tools to assess the reliability of self-organizing maps. Neural Networks 15, 967-978.

Fargione, J.E., Plevin, R.J., Hill, J.D., 2010. The Ecological Impact of Biofuels. Annu. Rev. Ecol. Evol. Syst. 41, 351-377.

Gasparatos, A., Stromberg, P., Takeuchi, K., 2011. Biofuels, ecosystem services and human wellbeing: Putting biofuels in the ecosystem services narrative. Agric. Ecosyst. Environ. 142, 111-128.

Klein, T., Holzkämper, A., Calanca, P., Seppelt, R., Fuhrer, J., 2013. Adapting agricultural land management to climate change: a regional multi-objective optimization approach. Landsc. Ecol. 28, 2029-2047.

Kohonen, T., 2008. Self-organizing maps. Springer Berlin Heidelberg.

Kollat, J.B., Reed, P.M., 2006. Comparing state-of-the-art evolutionary multi-objective algorithms for long-term groundwater monitoring design. Adv. Water Resour. 29, 792-807.

Kollat, J.B., Reed, P.M., 2007. A framework for Visually Interactive Decision-making and Design using Evolutionary Multi-objective Optimization (VIDEO). Environ. Model. Softw. 22, 1691-1704.

Lautenbach, S., Volk, M., Strauch, M., Whittaker, G., Seppelt, R., 2013. Optimization-based trade-off analysis of biodiesel crop production for managing an agricultural catchment. Environ. Model. Softw. 48, 98-112.

Maringanti, C., Chaubey, I., Popp, J., 2009. Development of a multiobjective optimization tool for the selection and placement of best management practices for nonpoint source pollution control. Water Resour. Res. 45, 1-15.

Neitsch, S.L., Arnold, J.G., Kiniry, J.R., Williams, J.R., 2005. Soil and Water Assessment Tool Documentation, Version 2005.

Nicklow, J., Asce, F., Reed, P.M., Asce, M., Savic, D., Dessalegne, T., Harrell, L., Chan-hilton, A., Karamouz, M., Minsker, B., Ostfeld, A., Singh, A., Zechman, E., 2010. State of the Art for Genetic Algorithms and Beyond in Water Resources Planning and Management 412-432.

Panagopoulos, Y., Makropoulos, C., Mimikou, M., 2012. Decision support for diffuse pollution management. Environ. Model. Softw. 30, 57-70.

Reed, P.M., Hadka, D., Herman, J.D., Kasprzyk, J.R., Kollat, J.B., 2013. Evolutionary multiobjective optimization in water resources: The past, present, and future. Adv. Water Resour. 51, 438-456.

Rodriguez, H.G., Popp, J., Maringanti, C., Chaubey, I., 2011. Selection and placement of best management practices used to reduce water quality degradation in Lincoln Lake watershed. Water Resour. Res. 47, 1-13.

Seppelt, R., Lautenbach, S., Volk, M., 2013. Identifying trade-offs between ecosystem services, land use, and biodiversity: a plea for combining scenario analysis and optimization on different spatial scales. Curr. Opin. Environ. Sustain. 5, 1-6.

Spekat, A., Enke, W., Kreienkamp, F., 2006. Neuentwicklung von regional hoch aufgelösten Wetterlagen für den Freistaat Sachsen und Bereitstellung regionaler Klimaszenarios auf der Basis. von globalen Klimasimulationen mit ECHAM5/MPIOM T63L312010 bis 2100 für die Szenarios B1, A1B und A2 (WEREX IV), Endbericht: Szenarios für das Einzugsgebiet der Parthe. Sächsisches Landesamt für Umwelt, Landwirtschaft und Geologie, Dresden.

Tilman, D., Socolow, R., Foley, J.A., Hill, J., Larson, E., Lynd, L., Pacala, S., Reilly, J., Searchinger, T., Somerville, C., Williams, R., 2009. Beneficial Biofuels-The Food, Energy, and Environment Trilemma. Science (80-. ). 325, 270-271.

Whittaker, G.W., 2005. Application of SWAT in the evaluation of salmon habitat remediation policy. Hydrol. Process. 19, 839-848. 